\title{
Modelling asthma in macaques: longitudinal changes in cellular and molecular markers
}

\author{
G. Ayanoglu*, B. Desai*, R.B. Fick Jr*, J. Grein*, R. de Waal Malefyt*, J. Mattson*, \\ T. McClanahan*, S. Olmstead ${ }^{\#}$, S.P. Reece ${ }^{\#}$, M.R. Van Scott ${ }^{\#}$ and R.L. Wardle ${ }^{\#}$
}

ABSTRACT: The aim of the present study was to determine whether systemic sensitisation and chronic aeroallergen challenge in macaques replicate the classical and emerging immunology and molecular pathology of human asthma.

Macaques were immunised and periodically challenged over 2 yrs with house dust mite allergen. At key time-points, serum, bronchoalveolar lavage (BAL) and bronchial biopsies were assayed for genes, proteins and lymphocyte subpopulations relevant to clinical asthma.

Immunisation and periodic airway challenge induced changes in immunoglobulin $E$, airway physiology and eosinophilia consistent with chronic, dual-phase asthma. Sensitisation increased interleukin (IL)-1 $\beta$ and -6 concentrations in serum, and IL-13 expression in BAL cells. Airway challenge increased: early expression of IL-5, $-6,-13$ and -19 , and eotaxin; and variable late-phase expression of IL-4, -5 and -13 , and thymus- and activation-regulated chemokine in BAL cells. CD4+ lymphocytes comprised $30 \%$ of the CD3+ cells in BAL, increasing to $50 \%$ in the late phase. Natural killer T-cells represented $<3 \%$ of the $\mathrm{CD} 3+$ cells. Corticosteroid treatment reduced serum histamine levels, percentage of CD4+ cells and monocyte-derived chemokine expression, while increasing CD3+ and CD8+ cells in BAL.

Sensitisation and periodic aeroallergen challenge of cynomolgus macaques results in physiological, cellular, molecular and protein phenotypes, and therapeutic responses observed in human asthma, providing a model system useful in target and biomarker discovery, and translational asthma research.

KEYWORDS: Asthma, corticosteroid treatment, natural killer T-cell, primate model

A sthma continues to present a significant unmet medical need [1] and the search for effective asthma drugs with novel mechanisms of action continues. Nonhuman primate models most closely replicate the genetics, physiology, immunology and pathology of the human disease [2-4]. The availability of these models uniquely allows examination of both induction of chronic allergy-driven airway inflammation and bronchoconstriction in a controlled setting, as well as identification of key mediators for the maintenance of chronic asthma. Additionally, these models provide a platform to assess pre-clinical safety, and proof of activity and efficacy for novel asthma therapeutics, under conditions that are observed in human patients.

Models of asthma have been developed in a variety of common laboratory animals, including guinea pigs, rabbits, rats, mice, sheep, cats, dogs and macaques (see review by BICE et al. [5]).
However, there are significant differences in airway architecture and immune responses to chronic allergen between species. Few species develop spontaneous allergic sensitivity to allergens, chronic or prolonged immune and inflammatory responses following pulmonary allergen exposure, progressive worsening of airway responses with repeated antigen challenge, and significant accumulation of lymphoid cells outside the bronchial-associated lymphoid tissue. Murine models have been instrumental in elucidating and dissecting pathways involved in immune responses, but translation of findings in the mouse to development of therapeutics in humans has been largely unsuccessful. Nonhuman primates are more similar to humans in their genetics, anatomy, development and responses to pulmonary allergen challenge than other species. These animals are long-lived and can manifest symptoms of relapsing or remitting allergic asthma for years $[2,3,6]$, thereby providing a penultimate model for assessing safety and

\section{AFFILIATIONS}

*Depts of Bioanalytical and Protein Chemistry, Experimental Pathology and Pharmacology, and Immunology, Schering-Plough Biopharma, Palo Alto, CA,

\#Physiology Dept, Brody School of Medicine, East Carolina University, Greenville, NC, USA.

Contributors to the design, conduct, analysis and interpretation of these studies have been listed alphabetically.

CORRESPONDENCE

M.R. Van Scott

Dept of Physiology

The Brody School of Medicine

East Carolina University

6N98 Brody Building

600 Moye Boulevard

Greenville

NC 27834-4354

USA

E-mail: vanscottmi@ecu.edu

Received:

March 252010

Accepted after revision:

July 062010

First published online:

July 222010 
efficacy of novel therapeutics before clinical trials, as well as dissociating pathogenic factors involved in the induction and maintenance phases of the disease.

Previous reports have described findings in monkeys sensitive to Ascarus suum [2, 7-10]. A small number of primate studies have used clinically meaningful aeroallergens, such as ragweed [11] or house dust mite (HDM) delivered in aerosol form $[6,12,13]$. Plopper and Hyde [3] addressed the validity of these models at the anatomical and cellular levels, and Zou et al. [14] documented changes in gene expression by microarray profiling following acute challenge with allergen. While these studies have provided information on differential gene and protein expression before and after acute exacerbations (i.e. early- and late-phase responses), asthma is a chronic disease expressed over a lifetime, and little has been reported on longitudinal changes in gene and protein expression over longer periods of time under well-controlled conditions. The present study defines the chronic effects of HDM exposure on immune and inflammatory parameters relevant to human asthma. Starting with the HDM-naïve state, a small group of cynomolgus macaques were observed longitudinally through systemic immunisation with major mite antigens, Dermatophagoides pteronyssinus and Dermatophagoides farinae, followed by 12 months of periodic inhalation of HDM allergen. Effects of corticosteroid treatment were then defined in a larger group of HDM-sensitive animals that had been periodically challenged with aerosolised HDM over 18 months. Whole blood, bronchoalveolar lavage (BAL) and bronchial biopsies were obtained and assayed broadly using multiple analytic techniques, including examination of novel proinflammatory chemokine and cytokine ligands and receptors, and lymphocyte subsets isolated from the airways following allergen challenge. Highly sensitive real-time quantitative RT-PCR methods and multiplex protein analysis identified differentially expressed, canonical and novel mediators of T-helper cell type 2 responses and lung pathology. CD3+, CD4+, CD8+ and natural killer (NK) T-cells were enumerated during the early (EAR) and late (LAR) phases of the allergic response, and following corticosteroid treatment.

\section{METHODS}

Macaca fascicularis, 30-42 months of age, were purchased from Alphagenesis (Yemassee, SC, USA). Animal husbandry was conducted under US Department of Agriculture guidelines [15]. Initially, 10 animals were sensitised to HDM allergen as described later and five additional animals served as naïve or nonallergic controls. All protocols were approved by the Institutional Animal Care and Use Committee of East Carolina University (Greenville, NC, USA).

\section{Study design}

The protocol consisted of an exploration phase, in which a small number of allergic and HDM-naïve animals were studied to identify traditional and novel biomarkers of asthma, and a validation phase, in which observations made during the exploration phase were confirmed in a larger number of allergic animals (fig. 1). Animals were sensitised to HDM allergen over a 7.5-month period by subcutaneous injections of allergen (312 allergenic units (AU) D. pteronyssinus extract; Greer Laboratories, Lenoir, NC, USA) adsorbed to Alum
(Imject Alum; Pierce, Rockford, IL, USA) administered at 2week intervals until HDM-specific immunoglobulin (Ig)E titres approached the level of allergic control serum, and then at 4week intervals until the first aeroallergen challenge. Following sensitisation, the animals were challenged with nebulised HDM (1-2,500 AU $\cdot \mathrm{mL}^{-1}$ D. pteronyssinus and D. farinae extract for $4 \mathrm{~min}$ ) at a concentration that induced $100 \%$ increase in lung resistance $(R \mathrm{~L}), 40 \%$ decrease in dynamic lung compliance $(\mathrm{CL}, \mathrm{dyn})$, or decline in arterial oxygen saturation measured by pulse oximetry $\left(\mathrm{Sp}, \mathrm{O}_{2}\right)$ to $\leqslant 70 \%$. Airway inflammation and responses to nebulised methacholine $24 \mathrm{~h}$ after allergen challenge were measured periodically to assess development of LAR.

\section{Exploration phase}

Proteogenomic analyses were conducted before and after induction of the asthmatic phenotype in three HDM-sensitised animals (two females and one male) exhibiting high HDMspecific IgE titres. Samples from five nonallergic animals (all female) were evaluated in parallel. As discussed in detail in the Results section, one of the nonallergic control animals, DL8A, was found to be intrinsically sensitive to HDM and was later classified and studied as a passively sensitised subject. Blood, serum, BAL and bronchoscopic biopsy samples were analysed to assess traditional and novel asthma disease biomarkers.

\section{Validation phase}

Seven animals (two females and five males) exhibiting high HDM-specific IgE titres were chronically challenged with nebulised HDM over the course of 17 months. During the final months, the animals were challenged at 4-week intervals, and every 8 weeks ( $24 \mathrm{~h}$ after allergen aerosol administration) the

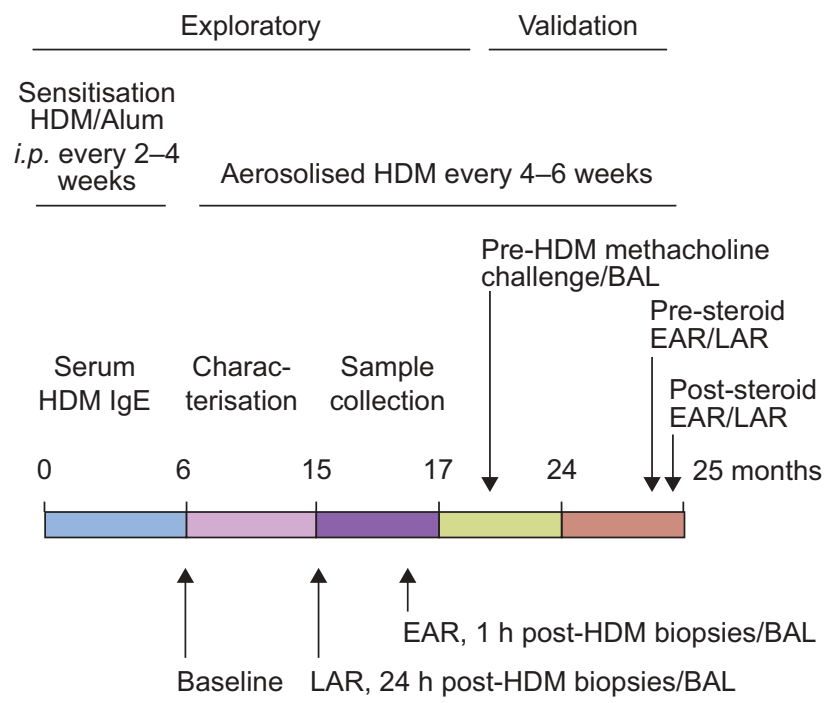

FIGURE 1. Study design. Animals were sensitised to house dust mite antigen (HDM) for 6 months, then periodically challenged with aerosolised HDM. Four animals underwent proteogenomic characterisation during the exploratory phase (three actively sensitised and DL8A, which was instrinsically sensitive); seven others underwent steroid treatment during the validation phase. Early and late allergic responses (EAR and LAR, respectively) were monitored periodically beyond month 6. BAL: bronchoalvelolar lavage; Ig: immunoglobulin. 
animals were challenged with methacholine and the lungs lavaged. Following the last LAR sample collection, the animals were treated with methylprednisolone sodium acetate (DepoMedrol; $4.5 \mathrm{mg} \cdot \mathrm{kg}^{-1}$ i.m. once-weekly for 2 weeks) followed by methylprednisolone sodium succinate (Solu-Medrol; $10 \mathrm{mg} \cdot \mathrm{kg}^{-1}$ i.v.). $1 \mathrm{~h}$ later, the animals were challenged with HDM, and EAR and LAR were assessed.

\section{Pulmonary function testing}

Subjects were anaesthetised with telazol $\left(2.5 \mathrm{mg} \cdot \mathrm{kg}^{-1}\right.$ i.m. $)$ and propofol $\left(10-15 \mathrm{mg} \cdot \mathrm{kg}^{-1} \cdot \mathrm{h}^{-1}\right.$ i.v.). An endotracheal tube and oesophageal balloon were inserted. $C \mathrm{~L}$,dyn and $R \mathrm{~L}$ were measured by standard computer analysis of the flow and pressure signals (MuMed PR800; MuMed, London, UK). Baseline parameters were recorded, saline was delivered via a DeVilbiss ultrasonic nebuliser (DeVilbiss Healthcare, Somerset, PA, USA) for $4 \mathrm{~min}$ prior to HDM provocation and for $2 \mathrm{~min}$ prior to methacholine provocation, the endotracheal tube was aspirated, and pulmonary function was monitored for $1 \mathrm{~min}$.

Increasing concentrations of HDM allergen (1, 10, 100, 500 and $2,500 \mathrm{AU} \cdot \mathrm{mL}^{-1}$ ) were delivered at 5 -min intervals until a $100 \%$ increase in $R \mathrm{~L}$ was observed. Pulmonary function was then monitored at 5-min intervals for $15 \mathrm{~min}$. Bronchoconstriction was reversed with aerosolised albuterol ( $0.083 \%$ for $4 \mathrm{~min})$. $\mathrm{Sp}_{\mathrm{p}} \mathrm{O}_{2}$, blood pressure and heart rate were monitored continuously. Supplemental $\mathrm{O}_{2}$ was administered as need to maintain $\mathrm{Sp}_{\mathrm{O}} \mathrm{O}_{2}$ above $70 \%$. Provocation was discontinued if $\mathrm{Sp}, \mathrm{O}_{2}$, blood pressure or heart rate were not maintained.

To assess airway hyperresponsiveness, methacholine was nebulised for $2 \mathrm{~min}$ in doubling doses between 0.001 and $10.24 \mathrm{mg} \cdot \mathrm{mL}^{-1}$. The provocative concentrations that induced a $100 \%$ increase in RL (PC100) and 40\% decrease in CL,dyn (PC40) were determined for each animal.

Endotracheal BAL and bronchial biopsy was performed on anaesthetised and intubated subjects (see online supplementary Materials and Methods).

\section{Immunoassays}

HDM-specific IgE was measured as previously reported [16]. Briefly, HDM-specific IgE levels in serum were reported as a percentage of the levels in historical allergic and naïve control serum samples. IgE levels in the control serum samples were quantified using a commercially available kit (Kit \#7070; Alpha Diagnostics International, San Antonio, TX, USA). The HDMpositive and -negative control sera had similar levels of total $\operatorname{IgE}\left(87\right.$ and $114 \mathrm{U} \cdot \mathrm{mL}^{-1}$, respectively, with the units being calibrated to the International Units for human $\operatorname{IgE}$ as established by the World Health Organization [17]). The amount of HDM-specific IgE in the control serum was quantified by repeating the assay on HDM-coated, serum-blocked plates using the Alpha Diagnostics reagents. The HDM-specific IgE titre in the allergic control serum was $13 \mathrm{U} \cdot \mathrm{mL}^{-1}$, compared to an undetectable level in naïve control serum (i.e. no difference from background in uncoated wells).

Serum and BAL histamine levels were determined using the Histamine ELISA Kit from MP Biomedicals, LLC (Santa Ana, CA, USA). Interleukin (IL)-1 $\beta,-4,-5,-6,-13$ and -8 were measured using the Luminex Multiplex Kit (Millipore
Corporation, Billerica, MA, USA). Eotaxin and monocytederived chemokine (MDC) concentrations were determined using an electrochemiluminescence biosensor assay (Meso Scale Discovery, Gaithersburg, MD, USA).

\section{Gene expression analysis}

Total RNA was isolated from whole blood using the PAXgene System (PreAnalytiX, Valencia, CA, USA) and from BAL cells using the RNeasy method (Qiagen, Valencia, CA, USA), according to the manufacturers' protocols. Total RNA was isolated from lung biopsy tissue using the Versagene ${ }^{\mathrm{TM}}$ RNA purification system (Gentra Systems, Minneapolis, MN, USA).

Total RNA from blood and BAL cells was reverse-transcribed using the Quantitect ${ }$ reverse transcription method (Qiagen, Valencia, CA, USA). Total RNA from lung biopsy tissue was reverse-transcribed using WT-Ovation ${ }^{\mathrm{TM}}$ Pico System (NuGen Technologies, San Carlos, CA, USA). Primers were designed using the Primer Express software (Applied Biosystems (ABI), Foster City, CA, USA) or obtained commercially from ABI. Real-time quantitative PCR was performed on $10 \mathrm{ng}$ of cDNA from each sample using either of two methods, as previously reported [18]. Human primers for 153 different genes were used. Cross-reactivity of primer sets to nonhuman primate samples was tested on archived samples and was deemed acceptable for comparing between samples, but not for absolute quantitative measurements.

\section{Flow cytometric analysis}

BAL cells were enumerated, checked for viability (Vi-Cell Cell Viability Analyser, Beckman Coulter, Fullerton, CA, USA), blocked with human IgG (Sigma, St Louis, MO, USA) and normal mouse serum (Jackson Immuno-Research Laboratories, West Grove, PA, USA), and stained with fluorophore-conjugated monoclonal antibodies against CD3, CD4, CD8 and CD11b (BD Biosciences, San Jose, CA). NK T-cells were defined by staining with dimeric human CD1d-Ig (BD Biosciences) loaded with the glycolipid $\alpha$-galactosyl ceramide [19]. Propidium iodide was added at a concentration of $2 \mu \mathrm{g} \cdot \mathrm{mL}^{-1}$ to each cell sample $10 \mathrm{~min}$ prior to flow cytometry to distinguish live from dead cells (see online supplementary Figure E1 for representative flow cytometry plots). Data was acquired using a BD FACS Canto II flow cytometer equipped with FACS DiVa acquisition software for FACS Canto II, version 6.0 (BD Biosciences). A total of 1,000,000 events were recorded per sample.

\section{Statistical analysis}

Differences between groups were evaluated using paired t-tests or ANOVA, and Tukey's post hoc analysis was used as appropriate. Data for biomarkers were analysed in JMP Software (SAS Institute, Cary, NC, USA) using the Wilcoxon test. The level of significance was set at $\mathrm{p}<0.05$.

\section{RESULTS}

\section{Pulmonary physiological responses}

In the exploratory phase, three HDM-naïve subjects, and two animals that were injected and challenged with HDM antigen but did not develop HDM sensitivity were compared to three allergic asthmatic subjects (animals 1436, 5136, and 6447). One of the naïve controls, DL8A, exhibited a high serum anti-HDM IgE titre (71\% of allergic control serum) and low PC100 to methacholine $\left(0.76 \mathrm{mg} \cdot \mathrm{mL}^{-1}\right)$, both of which were equivalent to 
the actively-sensitised animals (table 1). Following collection of the initial biological samples, DL8A was intentionally exposed to HDM antigen, and developed robust EAR and LAR. DL8A was, therefore, reclassified as a passively sensitised allergic asthmatic subject. The remaining four nonallergic control animals exhibited low HDM-specific IgE titres $(24 \pm 12 \%$ of allergic control serum), few inflammatory cells in BAL $\left(6 \times 10^{6}\right.$ total cells, $0.2 \times 10^{6}$ eosinophils in the compartment) and high LAR PC100 to methacholine $\left(1.2 \pm 0.5 \mathrm{mg} \cdot \mathrm{mL}^{-1}\right.$ ) (see online supplementary Table E1 for the characteristics of control cohort). The two negative control animals that were exposed to HDM exhibited no appreciable bronchoconstriction (see online supplementary Table E1).

The HDM-responsive subjects exhibited progressive increases in HDM-specific IgE titres during sensitisation with HDM (see online supplementary Figure E2 for an IgE timecourse). Compared to the nonallergic controls, they exhibited high serum HDM-specific IgE titres, HDM-induced bronchoconstriction, hyperresponsiveness to methacholine $24 \mathrm{~h}$ after HDM exposure, and late-phase increases in BAL lymphocytes and eosinophils (table 1).

In the validation phase, HDM-sensitised animals were challenged with aerosolised HDM at 4-week intervals for 17 months. During the last 5 months, BAL samples were collected every 8 weeks, $24 \mathrm{~h}$ after HDM challenge. Following the final challenge and lavage, the animals were treated with methylprednisolone for 2 weeks. Steroid treatment decreased HDM-induced decreases in CL,dyn (table 1). Methacholine PC100 was increased, and the number of eosinophils and lymphocytes in BAL fluid was reduced.

\section{Gene expression analysis}

In the exploratory phase, animals were sensitised to HDM and specimens were collected. Animals were then challenged with aerosolised HDM every 4 weeks. LAR and EAR samples were collected after 9 months of periodic exposure to HDM. One subject, 6447, did not exhibit robust acute bronchoconstriction to HDM aeroallergen leading up the LAR time-point, so LAR samples were not collected for gene expression analysis.

Samples were screened on a selected set of 153 genes (see online supplementary Table E2 for the exploratory gene expression profile). Blood and mucosal biopsy samples failed to show consistent changes in gene expression, and the data are, therefore, not reported. BAL cells collected during EAR exhibited altered expression of numerous cytokines, including IL-4, -5, -13, -6, -8 and -19 (fig. 2a). IL-4 and -19, and thymusand activation-regulated chemokine (TARC; CCL17) were upregulated during LAR (fig. 2b).

Animal-to-animal variation was observed, but individual subjects exhibited consistent patterns of IL-4, -5 and -13 , and TARC expression (fig. 3a-d). Prior to aeroallergen challenge, low levels of IL-4 and -5 were expressed, similar to the nonallergic controls. In contrast, IL-13 was elevated. The passively sensitised animal, DL8A, exhibited the highest expression of IL-13 before intentional airway challenge (fig. 3b). All of the actively sensitised animals (1436, 5136 and 6447) exhibited higher levels of TARC expression than the nonallergic controls, whereas DL8A exhibited a level of expression equal to the controls (fig. 3d). Airway challenge increased expression of IL-5 and -13 during EAR (fig. $3 b$ and c). Expression of IL-4 increased in two out of three animals. The animal that did not

TABLE 1 Characteristics before and after allergen provocation for house dust mite allergen (HDM)-responsive cohorts

$\begin{array}{lcc}\text { HDM-responsive } & \text { Serum } & \text { Methacholine } \\ \text { subjects } & \alpha \text {-HDM IgE } & \mathrm{PC}_{100} \\ & \begin{array}{c}\text { allergic } \\ \text { control }\end{array} & \mathrm{mg} \cdot \mathrm{mL}^{-1} \\ & & \end{array}$

\begin{tabular}{ccccc}
\hline $\mathrm{HDM}$ & $\Delta R \mathrm{~L}$ & $\Delta \mathrm{CL}$,dyn & & Methacholine \\
$\mathrm{AU} \cdot \mathrm{mL}^{-1}$ & $\%$ & $\%$ & & $\mathrm{PC} 100$ \\
& & & & $\mathrm{mg} \cdot \mathrm{mL}^{-1}$
\end{tabular}

24 h after aerosolised HDM

EAR

Total Lymphocytes Eosinophils PMN

$\times 10^{6} \times 10^{6} \times 10^{6} \times 10^{6}$

\begin{tabular}{|c|c|c|c|c|c|c|c|c|c|c|}
\hline \multicolumn{11}{|l|}{ Exploratory } \\
\hline 1436 & 84 & 1.7 & 500 & 423 & -78 & 0.31 & 20.0 & 0.7 & 5.3 & 0.3 \\
\hline 5136 & 114 & 0.8 & 2500 & 329 & -65 & 0.57 & 20.0 & 2.1 & 3.0 & 1.1 \\
\hline 6447 & 96 & 1 & 2500 & 209 & -83 & 0.64 & 16.0 & 1.0 & 2.5 & 0.2 \\
\hline \multicolumn{11}{|l|}{ Validation group } \\
\hline Pre-steroid treatment ${ }^{+}$ & $74 \pm 6$ & $0.9 \pm 0.4$ & $762 \pm 327$ & $94 \pm 15$ & $-54 \pm 4$ & $0.32 \pm 0.10$ & $19.2 \pm 1.7$ & $0.7 \pm 0.1$ & $1.6 \pm 0.4$ & $0.6 \pm 0.4$ \\
\hline Post-steroid treatment & & & $519 \pm 368$ & $61 \pm 22$ & $-34 \pm 8^{*}$ & $0.60 \pm 0.18^{\star}$ & $14.9 \pm 1.2^{*}$ & $0.3 \pm 0.06^{*}$ & $0.8 \pm 0.3^{*}$ & $0.3 \pm 0.07$ \\
\hline \multicolumn{11}{|l|}{ Passively sensitised } \\
\hline DL8A & 71 & 0.76 & 500 & 300 & -73 & 0.27 & 16.0 & 0.4 & 1.4 & 0.9 \\
\hline
\end{tabular}

Data are presented as mean $\pm \mathrm{SE}$, unless otherwise stated. Ig: immunoglobulin; $\mathrm{PC} 100$ : provocative concentration that induced a $100 \%$ increase in lung resistance ( $R \mathrm{~L})$; EAR: early allergic response; $\triangle$ : HDM-induced change relative to the saline-induced response; $C L$,dyn: dynamic lung compliance; BAL: bronchoalveolar lavage; PMN: polymorphonuclear neutrophils. ${ }^{\#}$ : cells per millilitre of BAL returned $\times$ millilitres of BAL fluid instilled; ${ }^{\bullet}: n=7 ;{ }^{+}:$average over 5 months prior to steroid treatment. *: $p<0.05$ for effect of steroid treatment. 

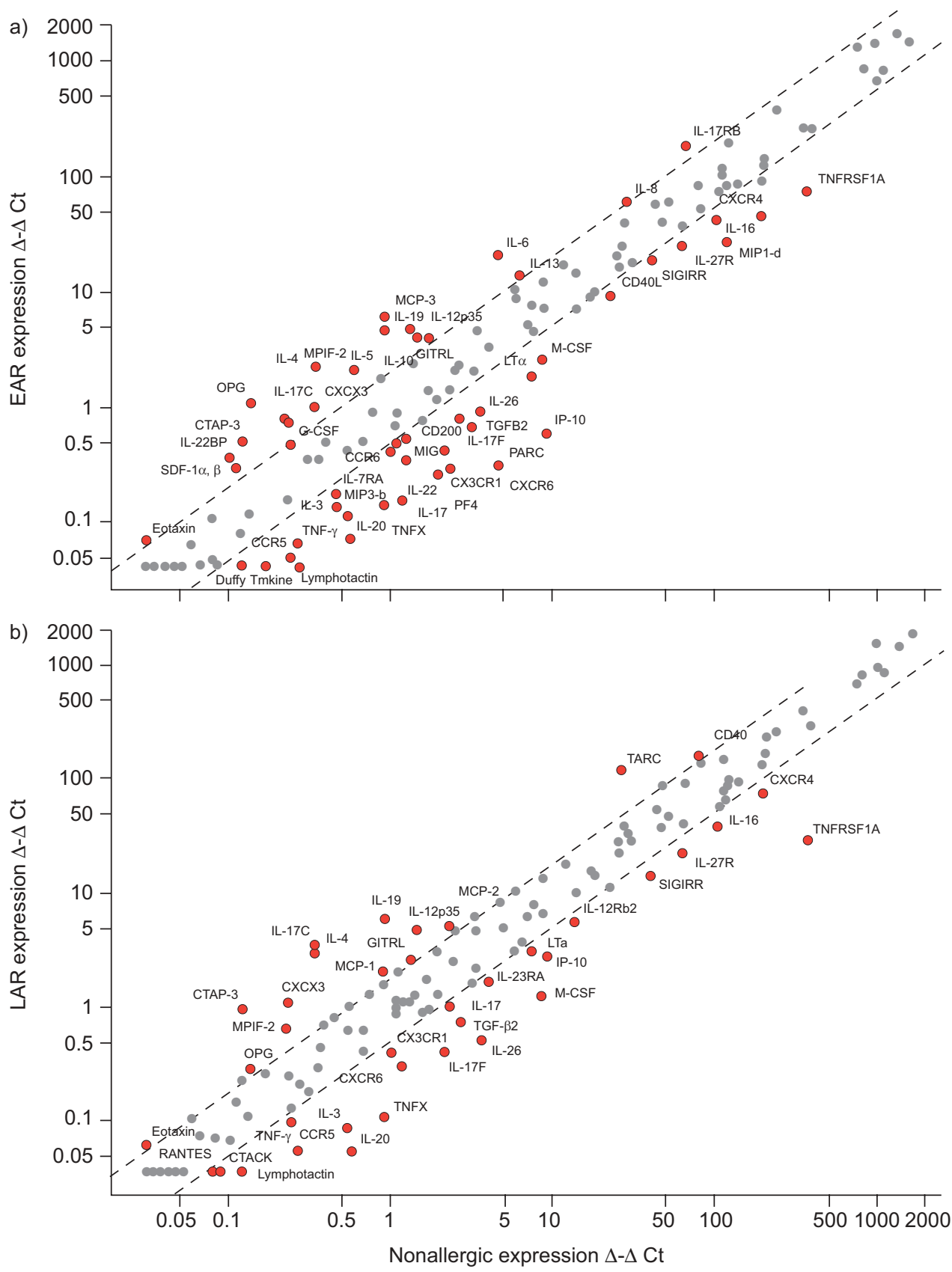

FIGURE 2. Gene expression profiles of bronchoalveolar lavage cells before and after aerosolised house dust mite allergen (HDM) challenge. Cells were collected from HDM-sensitised animals a) 60 min (early allergic response; EAR) and b) $24 \mathrm{~h}$ (late allergic response; LAR) after aerosolised HDM challenge. Expression of 153 genes was analysed by quantitative RT-PCR and mean $\Delta-\Delta$ Ct values were plotted against the values for nonallergic control subjects. -----: greater than two-fold change. Red symbols indicate greater than two-fold change. $n=2$ (EAR), $n=3$ ( $\angle A R)$ and $n=4$ (nonallergic control). Limit of detection $=1 . \Delta-\Delta C t$ is defined as the difference in the shifts of the threshold cycles for target and reference genes. IL: interleukin; TNF: tumour necrosis factor; R: receptor; SF: superfamily member; MIP: macrophage inhibitory protein: SIGIRR: single immunoglobulin IL-1R-related molecule; MCP: monocyte chemotactic protein; M: macrophage; CSF: colony-stimulating factor; MPIF: myeloid progenitor inhibitory factor; GITRL: glucocorticoid-induced TNF receptor ligand; LT: Iymphotoxin; OPG: osteoprotegerin; IP: interferon (IFN)- $\gamma$-interacting protein; CTAP: connective tissue-activating protein; G: granulocyte; MIG: monocyte induced by IFN- $\gamma$; PARC: pulmonary and activation-regulated chemokine; SDF: stromal cell-derived factor; PF: platelet factor; TARC: thymusand activation-regulated chemokine; RANTES: regulated on activation, normal T-cell expressed and secreted; CTACK: cutaneous T-cell attracting chemokine.

exhibit an increase in IL-4 during EAR was 6447, who exhibited the lowest physiological response to aeroallergen challenge (table 1). Two out of two animals exhibited decreases in IL-5 and -13 expressions between EAR and LAR (fig. $3 b$ and c), and increases in expression of TARC (fig. 3d).
In the validation phase, 28 genes were selected for expression analysis. BAL samples were collected $24 \mathrm{~h}$ after an aerosolised HDM challenge, the animals were treated with systemic steroids for 2 weeks, rechallenged, and samples were collected $24 \mathrm{~h}$ later. As in the exploratory phase, gene expression was 
a)

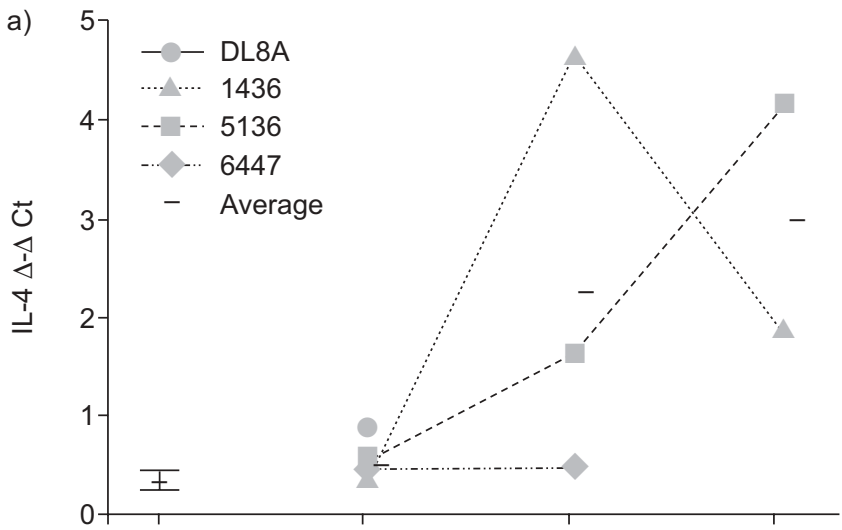

c)

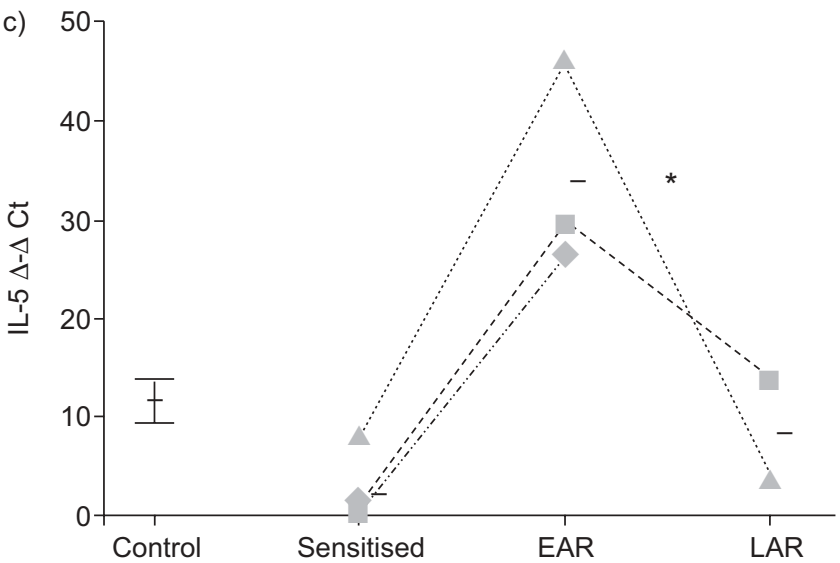

b)

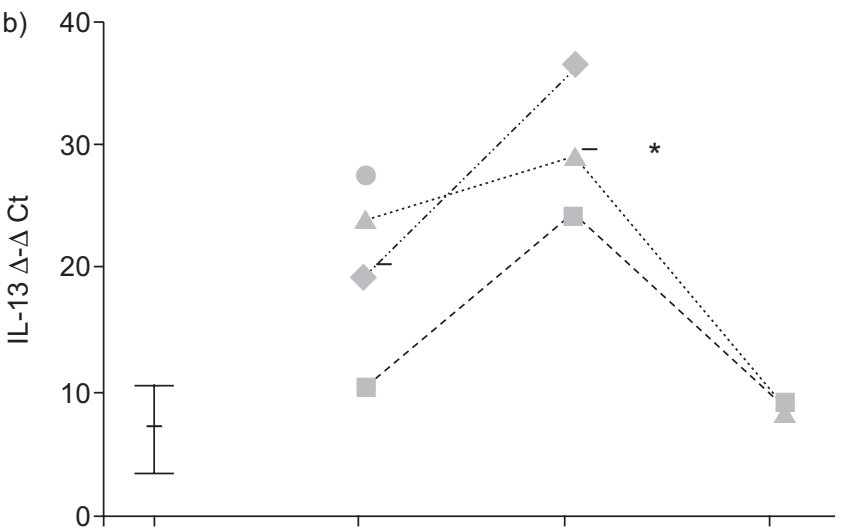

d)

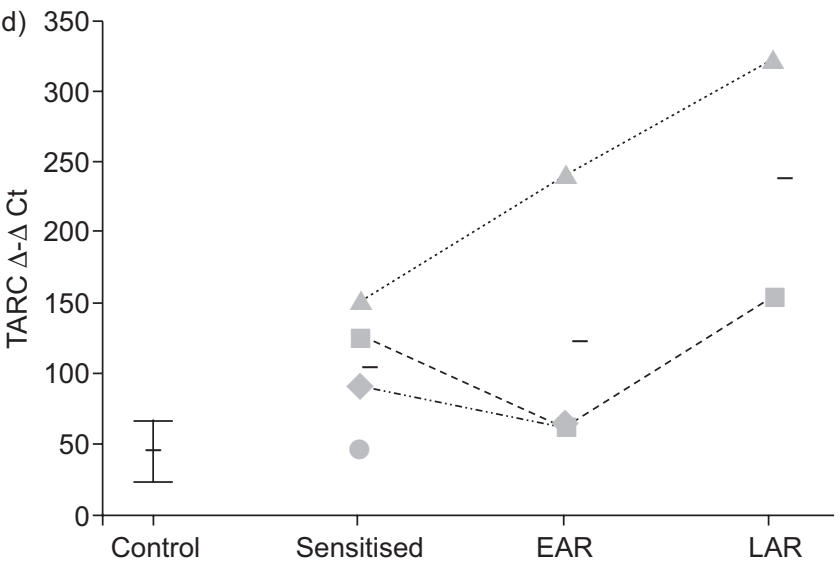

FIGURE 3. Gene expression in bronchoalveolar lavage cells from individual house dust mite allergen-challenged animals during the exploratory phase. a) Interleukin (IL)-4, b) IL-13, c) IL-5 and d) thymus- and activation-regulated chemokine (TARC) expression shown in figure 2 are replotted to show actual values for the allergic animals and mean \pm SE for four nonallergic control animals. $\Delta-\Delta \mathrm{Ct}$ is defined as the difference in the shifts of the threshold cycles for target and reference genes. EAR: early allergic response; LAR: late allergic response. *: $p<0.05$ for EAR versus sensitised.

variable during LAR, and no clear trends were observed in response to steroid treatment (see online supplementary Table E3 for normalised values of the validation data).

\section{Protein levels in serum and BAL}

In the exploratory phase, levels of IL- $1 \beta,-4,-5,-6,-8,-13$, and MDC and eotaxin proteins were determined in serum and BAL samples. IL-4, -5 and -13 were below threshold values for the assays ( $<80,16$ and $16 \mathrm{pg} \cdot \mathrm{mL}^{-1}$, respectively). Serum IL-1 $\beta$ and -6 were elevated following sensitisation, did not change during EAR and decreased during LAR (fig. $4 \mathrm{a}$ and b). In contrast, BAL IL-1 $\beta$ and -6 were low, similar to nonallergic controls prior to intentional airway challenge (fig. $5 a$ and b). Within 60 min of aerosol HDM challenge, levels of IL-6 and -8, and eotaxin in BAL increased in three out of four animals (fig. 5b-d). As reported for gene expression, the subject with the lowest sensitivity and responsiveness to HDM, 6447, was the outlier. In LAR samples, cytokine levels were variable.

In the validation phase, steroid treatment decreased EAR serum histamine levels (fig. 6a). MDC levels were highly variable and often high before steroid treatment, but consistently low following steroid treatment (fig. 6b). The three animals exhibiting the highest eotaxin levels prior to steroid treatment showed decreases in eotaxin following treatment, but no consistent change was observed across the cohort (fig. 6c).

\section{Flow cytometric analysis of BAL cells}

Multiparameter flow cytometric analysis was used to identify lymphocyte subpopulations in BAL during EAR and LAR. Representative data are shown in online supplementary Figure E1. Lymphocytes constituted $2-5 \%$ of total BAL cells (table 1). CD3+ cells represented $\leqslant 55 \%$ of the live cells in the lymphocyte scatter gate. The percentage of CD4+ BAL cells were higher in LAR than in EAR (fig. 7d). The number of CD4+ cells was not different (data not shown).

Of the CD3+ cells, NK T-cells represented a small subpopulation $(<3 \%)$ during EAR (fig. $7 \mathrm{j})$, and the percentage of NK Tcells decreased during LAR. CD3+ (fig. 7a, b and c) and CD8+ T-cells (fig. $7 \mathrm{~g}, \mathrm{~h}$ and i) were significantly increased during LAR (fig. 7a and g) following steroid treatment (fig. 7b, c, h and i). Concurrently, the percentage of CD4+ cells decreased following steroid treatment. NK T-cells did not change.

\section{DISCUSSION}

Previous reports have addressed developmental [3], genetic [14] and functional [12-14, 16] attributes of nonhuman primate 

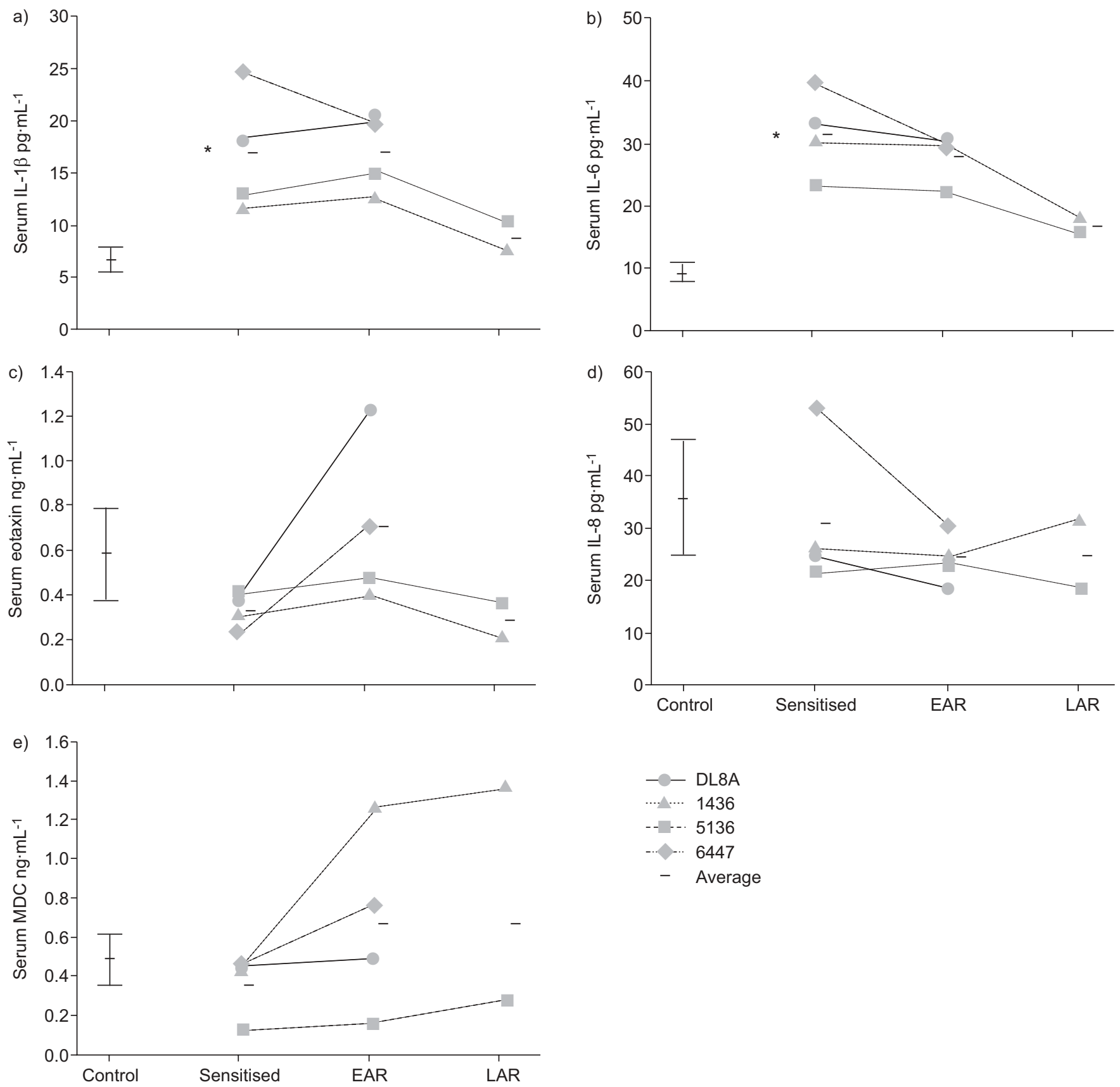

FIGURE 4. Serum protein levels measured in the exploratory phase. a) Interleukin (IL)-1 $1 \beta$, b) IL-6, c) eotaxin, d) IL-8 and e) monocyte-derived chemokine (MDC) were measured in nonallergic control animals and house dust mite allergen-sensitive animals before (sensitised) and after 9 months of periodic aeroallergen challenge. Early and late allergic response (EAR and LAR, respectively) samples were collected after aeroallergen challenge. Data for nonallergic control animals are presented as mean $\pm \mathrm{SE}$ $(n=4) .{ }^{*}: p<0.05$ for both sensitised and EAR versus control.

models of asthma. This follow-up report: 1) systematically addresses molecular, cellular and protein changes, longitudinally and at different times in development: 2) documents corticosteroid effects following establishment of chronic disease; and 3) defines changes in NK T-cell subset numbers in the chronic allergic asthma state.

One goal of this project was to provide predictive measures for manifestation of allergic asthma symptoms in cynomolgus macaques and, thereby, facilitate assignment of subjects to experimental groups in prospective studies. Similarly to humans and outbred animals, it is difficult to predict which subjects will develop allergic asthma symptoms and to predict the timecourse of disease manifestations in a given subject. We monitored levels of serum HDM-specific IgE to identify animals for assessment of gene and protein expression early in disease pathogenesis. However, one of the animals with the highest HDM-specific IgE concentrations, 6447, was slow in developing early-phase symptoms. In addition, one of the animals assigned as a naïve control, DL8A, appeared to be 

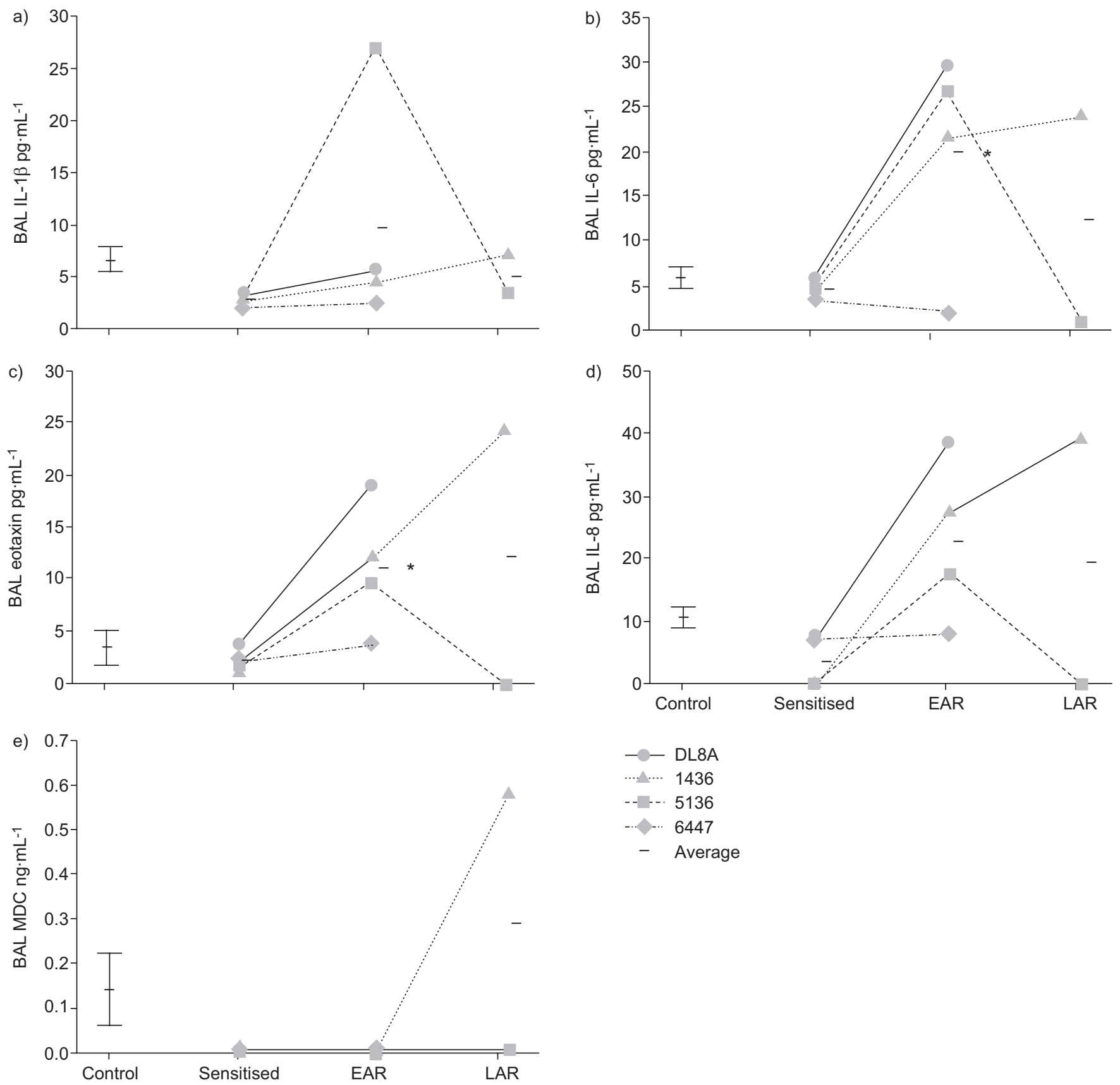

FIGURE 5. Bronchoalveolar lavage (BAL) fluid proteins in the exploratory phase. a) Interleukin (IL)-1 $\beta$, b) IL-6, c) eotaxin, d) IL-8 and e) monocyte-derived chemokine (MDC) were measured in nonallergic control animals and house dust mite allergen-sensitive animals before (sensitised) and after 9 months of periodic aeroallergen challenge. Early and late allergic response (EAR and LAR, respectively) samples were collected after aeroallergen challenge. Data for nonallergic control animals are presented as mean \pm SE $(n=4) .{ }^{*}: p<0.05$ for EAR versus sensitised.

predisposed to developing allergic asthma symptoms. While the findings of this study, particularly the finding that IL-13 gene expression is an early predictor, may facilitate a priori selection of animals for sensitisation, the model remains most appropriate for studies of established disease, where the animals can be fully characterised prior to testing therapeutic candidates. With the induction of a robust allergic asthmatic response, the disease symptoms remain remarkably stable, provided that the environment remains constant and exposure to allergen (both concentration and periodicity) is controlled.
Gene expression analysis of BAL cells revealed consistent patterns of induction of Th2-related signature genes including IL-4, -5 and -13 , and TARC. Due to the highly sensitive nature of real-time quantitative PCR, we were able to detect changes in these genes that were below the limit of detection in BAL by protein assays (in the case of IL-4, -5 and -13 ), and were not assayable in nonhuman primates by protein analysis due to lack of reagents (in the case of TARC). Whole-blood gene expression analysis from these animals did not show significant or consistent changes in response to challenge, and 

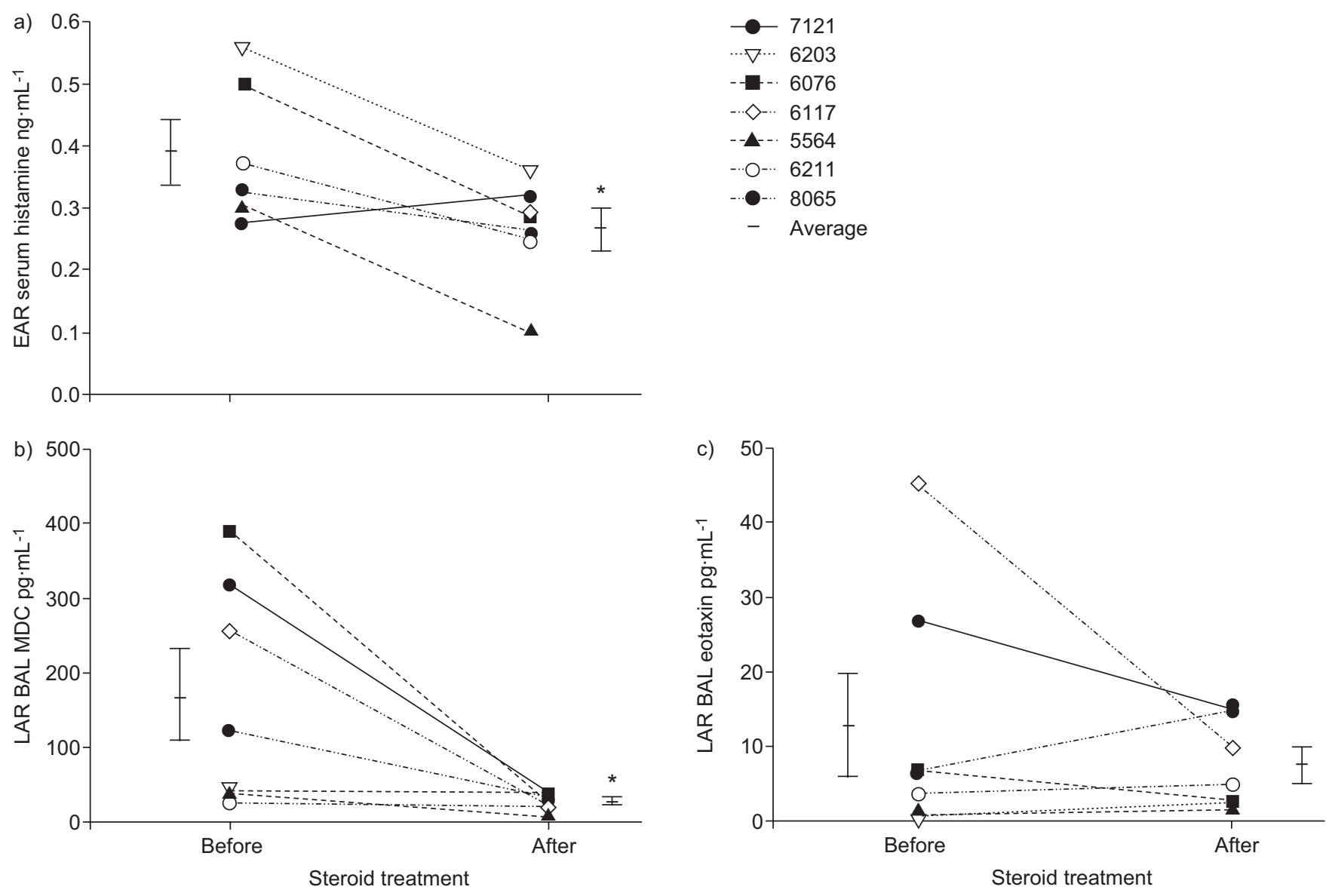

FIGURE 6. Effects of steroid treatment on a) serum histamine, and bronchoalveolar lavage (BAL) b) monocyte-derive chemokine (MDC) and c) eotaxin. Early and late allergic response (EAR and LAR, respectively) readouts were recorded in house dust mite allergen (HDM)-sensitive and periodically challenged animals before and after 2 weeks of steroid treatment. Serum histamine was measured $20 \mathrm{~min}$ after HDM challenge. MDC and eotaxin levels in BAL were measured $24 \mathrm{~h}$ after challenge. *: $\mathrm{p}<0.05$ for post-steroid treatment value versus pre-treatment value.

many genes were below the limit of detection in whole blood, in contrast to BAL cells. Lung biopsies from these animals showed highly variable expression patterns, probably due to sampling differences, tissue heterogeneity and variability introduced by linear amplification. This study shows that measuring gene expression from BAL cells is a sensitive and reproducible method to assess Th2 gene signatures in this model.

Following immunisation (or passive sensitisation, in the case of DL8A) but before intentional airway exposure to allergen, IL$1 \beta$ and -6 proteins were elevated in serum. These two general inflammatory, acute-phase cytokines are elevated in human allergy and reduced following immunotherapy [20, 21]. Gene expression of Th2-specific cytokines was increased in the airways within $60 \mathrm{~min}$ of allergen exposure. The early increase in Th2 cytokine expression was followed by an increase in eotaxin expression and eosinophils in the airways $23 \mathrm{~h}$ later. In human BAL fluid, Th2 cytokine concentrations increase over 24-42 h following segmental allergen challenge [22]. However, as in the present study, variability of Th2 cytokine expression increases with time after allergen challenge in humans [22].

It has been proposed that NK T-cells mediate Th2 inflammatory responses and may be a viable target in treating asthma
$[23,24]$. VIJAYANAND et al. [25] reported low numbers of NK Tcells in human asthmatic airways, whereas AKBARI et al. [23] reported that the majority of CD4+ cells in the airway lumen are NK T-cells. We found that the subpopulation of invariant NK T-cells in BAL fluid is small, indicating that large numbers of these cells are not required to sustain an allergic asthmatic phenotype.

CD4+ and CD8+ lymphocytes are elevated in blood and BAL of patients with allergic asthma [26-28]. Likewise, the nonhuman primates in this study exhibited increases in CD4+ cells in BAL during LAR. Interestingly, ROBINSON et al. [29] reported activation of CD4+ T cells in humans with allergic asthma and postulated that cytokines produced by activated Th2-type CD4+ T-cells may contribute to LAR. Th1 and Th2 responses, including cytokine- and chemokine-mediated responses, are well documented in allergic asthma [30-32]. Our observations indicate that activation state might be more critical than absolute numbers of $\mathrm{T}$-cell subpopulations in establishing chronic disease.

Corticosteroids are the most effective anti-inflammatory therapy in asthma, broadly inhibiting effector function of Th2 cells and eosinophils. In the present study, corticosteroid treatment 

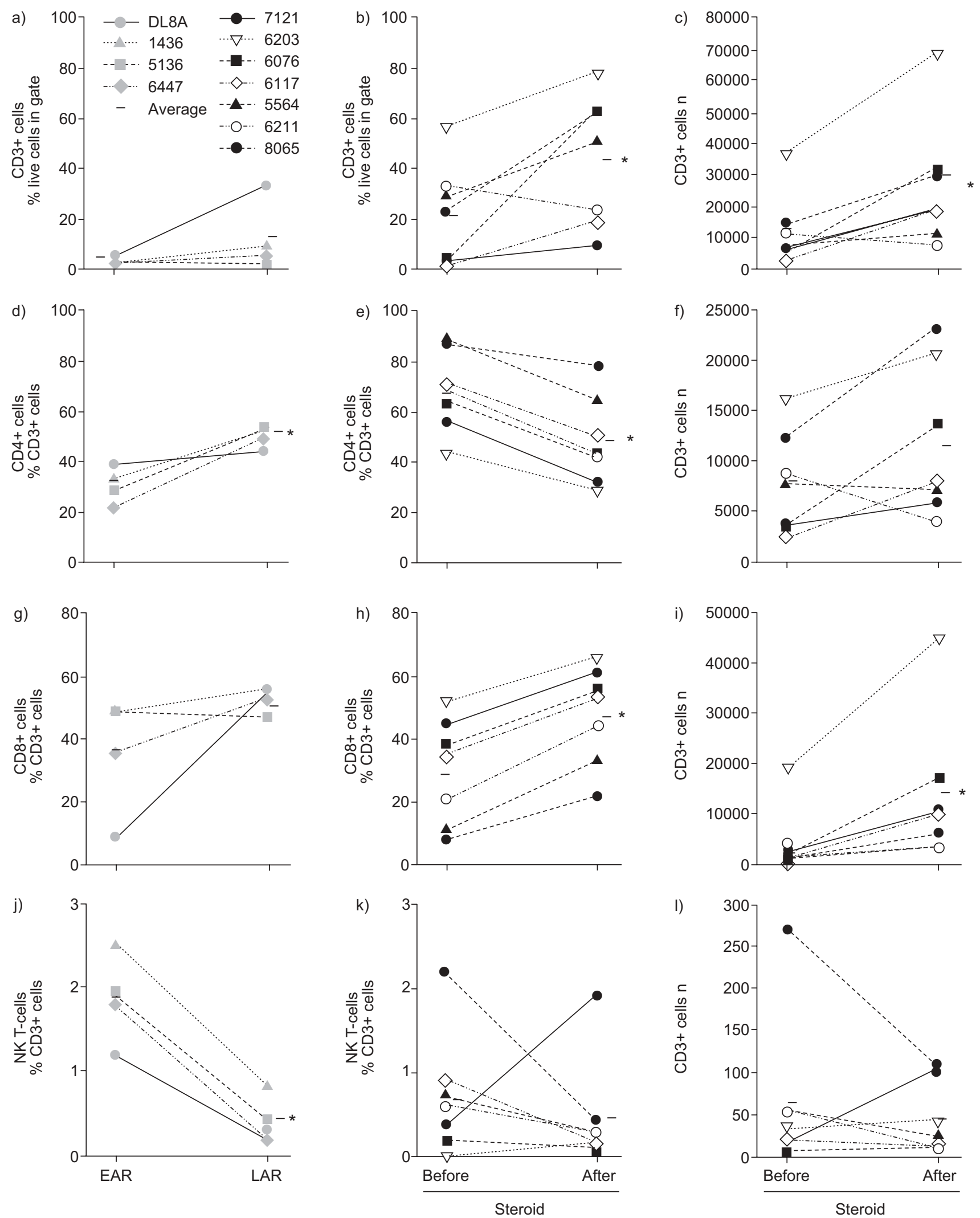

FIGURE 7. Lymphocyte subpopulation in bronchoalveolar lavage (BAL) of house dust mite allergen-sensitive animals. a, d, g, j) Exploratory phase: BAL was collected 60 min (early allergic response; EAR) or $24 \mathrm{~h}$ (late allergic response; LAR) after aeroallergen challenge. b, c, e, f, h, i, k, l) Validation phase: BAL was collected $24 \mathrm{~h}$ after allergen challenge, before and after 2 weeks of steroid treatment. a-c) CD3+, d-f) CD4+, g-i) CD8+ and $j-l$ ) natural killer (NK) T-cells were enumerated by flow cytometry. *: $p<0.05$ EAR versus LAR, or before versus after steroid treatment. 
inhibited LAR more than EAR, reducing: 1) serum histamine associated with acute bronchoconstriction; 2) methacholine sensitivity (i.e. increased PC100); 3) airway inflammation; and 4) MDC concentration in BAL fluid, all mirroring the efficacy of corticosteroid treatment in asthmatic subjects. Interaction of MDC with CCR4 is thought to recruit Th2 lymphocytes to target tissues [33]. MDC has been reported to be elevated in allergic rhinitis [34] and severe asthma [35]. However, not all investigators have observed an elevation in this chemokine, and at least one study revealed a small increase in MDC concentration in exhaled breath condensates in patients treated with inhaled corticosteroid treatment [36].

Recent studies have shown that corticosteroids inhibit the development of regulatory T-cells (Treg) and tolerance to allergens in mice, thereby enhancing subsequent Th2 responses and aggravating the course of asthma and allergic diseases [37]. Other investigators have also reported an expansion in T-cells after steroid treatment in asthma patients [38]. These findings are in agreement with our observations that CD3+ and CD8+ cells were higher after steroid treatment. Furthermore, inhibition of Treg cells may account for the increased variability in Th2 cytokine expression following steroid treatment in the present study.

Validated animal models that closely mirror human disease mitigate the risk intrinsic to translating basic research observations into clinical practice. The results of this study demonstrate that HDM-sensitive macaques periodically exposed to aerosolised allergen over extended periods of time exhibit allergen-induced changes in airway physiology and immunology that are similar to those seen in human asthmatics. Robust physiological and inflammatory responses are observed coincident with low numbers of NK T-cells, indicating that large numbers of these cells are not required to express an asthmatic phenotype. In HDM-sensitive animals whose airways have been primed with aerosolised allergen over time, Th2 cytokine gene expression in the airways increases within hours after an allergen challenge. However, the timecourse of expression is highly dependent on the individual and this source of variation should be accounted for when designing preclinical studies where cytokine expression is a primary readout. In conclusion, chronic periodic exposure of nonhuman primates to HDM closely models human atopic asthma and should be a valuable tool in discovery and translational research.

\section{STATEMENT OF INTEREST}

Statements of interest for G. Ayanoglu, B. Desai, R.B. Fick Jr, J. Grein, R. de Waal Malefyt, J. Mattson, T. McClanahan and M.R. Van Scott can be found at www.erj.ersjournals.com/site/misc/statements.xhtml

\section{ACKNOWLEDGEMENTS}

The authors wish to recognise the leadership of J. Curnutte and administrative support of S. Nottage. The technical support of K. Jensen, E. Murphy and L. Raskin, and the assistance of J.A. Katheiser (all ScheringPlough Biopharma, Palo Alto, CA USA) is also appreciated.

\section{REFERENCES}

1 World Health Organization. WHO Fact Sheet: Bronchial Asthma. Geneva, WHO, 2000.

2 Patterson R, Harris KE. IgE-mediated rhesus monkey asthma: natural history and individual animal variation. Int Arch Allergy Immunol 1992; 97: 154-159.
3 Plopper CG, Hyde DM. The non-human primate as a model for studying COPD and asthma. Pulm Pharmacol Ther 2008; 21: 755-766.

4 Coffman RL, Hessel EM. Nonhuman primate models of asthma. J Exp Med 2005; 201: 1875-1879.

5 Bice DE, Seagrave JC, Green FHY. Animal models of asthma. Inhal Tox 2000; 12: 829-862

6 Van Scott MR, Aycock D, Cozzi E, et al. Separation of bronchoconstriction from increased ventilatory drive in a nonhuman primate model of chronic allergic asthma. J Appl Physiol 2005; 99: 2080-2086.

7 Turner CR, Spannhake EW. Acute topical steroid administration blocks mast cell increase and the late asthmatic response of the canine peripheral airways. Am Rev Respir Dis 1990; 141: 421-427.

8 Pritchard DI, Eady RP, Harper ST, et al. Laboratory infection of primates with Ascaris suum to provide a model of allergic bronchoconstriction. Clin Exp Immunol 1983; 54: 469-476.

9 Gundel RH, Gerritsen ME, Gleich GJ, et al. Repeated antigen inhalation results in a prolonged airway eosinophilia and airway hyperresponsiveness in primates. J Appl Physiol 1990; 68: 779-786.

10 Young SS, Ritacco G, Skeans S, et al. Eotaxin and nitric oxide production as markers of inflammation in allergic cynomolgus monkeys. Int Arch Allergy Immunol 1999; 120: 209-217.

11 Renz H, Enssle K, Lauffer L, et al. Inhibition of allergen-induced IgE and IgG1 production by soluble IL-4 receptor. Int Arch Allergy Immunol 1995; 106: 46-54.

12 Yasue M, Nakamura S, Yokota T, et al. Experimental monkey model sensitized with mite antigen. Int Arch Allergy Immunol 1998; 115: 303-311.

13 Schelegle ES, Gershwin LJ, Miller LA, et al. Allergic asthma induced in rhesus monkeys by house dust mite (Dermatophagoides farinae). Am J Pathol 2001; 158: 333-41.

14 Zou J, Young S, Zhu F, et al. Microarray profile of differentially expressed genes in a monkey model of allergic asthma. Genome Biol 2002; 3: research0020.

15 US Department of Agriculture. National Research Council Guide for the Care and Use of Laboratory Animals. Washington, National Academy Press, 1996.

16 Van Scott MR, Hooker JL, Ehrmann D, et al. Dust miteinduced asthma in cynomolgus monkeys. J Appl Physiol 2004; 96: 1433-1444.

17 World Health Organization. WHO International Biological Reference Preparations. www.who.int/bloodproducts/catalogue/AlphJan10. pdf Date last accessed: December 3, 2010. Date last updated: January 4, 2010.

18 Wilson JH, Boniface K, Chan JR, et al. Development, cytokine profile and function of human interleukin 17-producing helper T cells. Nat Immunol 2007; 8: 950-957.

19 Naidenko OV, Maher JK, Ernst WA, et al. Binding and antigen presentation of ceramide-containing glycolipids by soluble mouse and human CD1d molecules. J Exp Med 1999; 190: 1069-1080.

20 Stone SF, Cotterell C, Isbister GK, et al. Elevated serum cytokines during human anaphylaxis: identification of potential mediators of acute allergic reactions. J Allergy Clin Immunol 2009; 124: 786-792.

21 De Amici M, Puggioni F, Casali L, et al. Variations in serum levels of interleukin (IL)-1 $\beta$, IL-2, IL- 6 , and tumor necrosis factor- $\alpha$ during specific immunotherapy. Ann Allergy Asthma Immunol 2001; 86: 311-313.

22 Lommatzsch M, Julius P, Kuepper M, et al. The course of allergeninduced leukocyte infiltration in human and experimental asthma. J Allergy Clin Immunol 2006; 118: 91-97.

23 Akbari O, Faul JL, Hoyte EG, et al. $\mathrm{CD}^{+}$invariant T-cell-receptor ${ }^{+}$ natural killer T cells in bronchial asthma. $N$ Engl J Med 2006; 354: 1117-1129.

24 Lisbonne M, Diem S, de Castro Keller A, et al. Cutting edge: invariant $\mathrm{V}$ alpha 14 NKT cells are required for allergen-induced 
airway inflammation and hyperreactivity in an experimental asthma model. J Immunol 2003; 171: 1637-1641.

25 Vijayanand P, Seumois G, Pickard C, et al. Invariant natural killer $\mathrm{T}$ cells in asthma and chronic obstructive pulmonary disease. N Engl J Med 2007; 356: 1410-1422.

26 Arnold V, Balkow S, Staats R, et al. Increase in perforin-positive peripheral blood lymphocytes in extrinsic and intrinsic asthma. Am Respir Crit Care Med 2000; 161: 182-186.

27 Walker C, Bode E, Boer L, et al. Allergic and nonallergic asthmatics have distinct patterns of T-cell activation and cytokine production in peripheral blood and bronchoalveolar lavage. Am Rev Respir Dis 1992; 146: 109-115.

28 Wahlstrom J, Dahlen B, Thre E, et al. Selective $\mathrm{CD} 8^{+} \mathrm{T}$ cells accumulate in the lungs of patients with allergic asthma after allergen bronchoprovocation. Clin Exp Immunol 1998; 112: 1-9.

29 Robinson D, Hamid Q, Bentley A, et al. Activation of CD4 $4^{+} \mathrm{T}$ cells, increased $\mathrm{T}_{\mathrm{H} 2}$-type cytokine mRNA expression, and eosinophil recruitment in bronchoalveolar lavage after allergen inhalation challenge in patients with atopic asthma. J Allergy Clin Immunol 1993; 92: 313-324.

30 Bakakos P, Pickard C, Smith JL, et al. TCR usage and cytokine expression in peripheral blood and BAL T cells. Clin Exp Immunol 2002; 128: 295-301.
31 Corry DB. Emerging immune targets for the therapy of allergic asthma. Nat Rev Drug Discov 2002; 1: 55-64.

32 Corrigan CJ, Kay AB. Asthma. Role of T-lymphocytes and lymphokines. British Med Bulletin 1992; 48: 72-84.

33 Romagnani S. Cytokines and chemoattractants in allergic inflammation. Mol Immunol 2002; 38: 881-885.

34 Yanai M, Sato K, Aoki N, et al. The role of CCL22/macrophagederived chemokine in allergic rhinitis. Clin Immunol 2007; 125 291-298.

35 Ying S, O'Connor B, Ratoff J, et al. Expression and cellular provenance of thymic stromal lymphopoietin and chemokines in patients with severe asthma and chronic obstructive pulmonary disease. J Immunol 2008; 181: 2790-2798.

36 Ko FW, Lau CY, Leung TF, et al. Exhaled breath condensate levels of eotaxin and macrophage-derived chemokine in stable adult asthma patients. Clin Exp Allergy 2006; 36: 44-51.

37 Stock P, Akbari O, DeKruyff RH, et al. Respiratory tolerance is inhibited by the administration of corticosteroids. J Immunol 2005; 175: 7380-7387.

38 Spinozzi F, Agea E, Bistoni $\mathrm{O}$, et al. Increased allergenspecific, steroid-sensitive gamma delta $\mathrm{T}$ cells in bronchoalveolar lavage fluid from patients with asthma. Ann Int Med 1996; 124: 223-228. 